Research Article

\title{
Development of a Pulsed Xenon Ultraviolet Disinfection Device for Real-Time Air Disinfection in Ambulances
}

\author{
Li Song $\mathbb{D}^{1,2,3}$ Wei Li, ${ }^{2}$ Jian'an He, ${ }^{2,4}$ Lang Li, ${ }^{1,2}$ Tao Li, ${ }^{5}$ Dayong Gu $\left(D^{6}{ }^{6}\right.$ \\ and Huanwen Tang ${ }^{1}$ \\ ${ }^{1}$ Department of Environmental and Occupational Health, Dongguan Key Laboratory of Environmental Medicine, \\ School of Public Health, Guangdong Medical University, Dongguan 523808, China \\ ${ }^{2}$ Central Laboratory of Health Quarantine, Shenzhen International Travel Health Care Center, Shenzhen Customs District, \\ Shenzhen 518033, China \\ ${ }^{3}$ Shenzhen Pingle Orthopedic Hospital, Shenzhen 518010, China \\ ${ }^{4}$ Shenzhen Academy of Inspection and Quarantine, Shenzhen 518010, China \\ ${ }^{5}$ School of Mechanical Engineering, Hebei University of Technology, Tianjin 300130, China \\ ${ }^{6}$ Department of Laboratory Medicine, Shenzhen Second People's Hospital, The First Affiliated Hospital of Shenzhen University, \\ Health Science Center, Shenzhen 518035, China
}

Correspondence should be addressed to Dayong Gu; wanhood@163.com and Huanwen Tang; thw@gdmu.edu.cn

Received 19 August 2019; Revised 19 October 2019; Accepted 3 December 2019; Published 24 February 2020

Academic Editor: Kheng-Lim Goh

Copyright ( 92020 Li Song et al. This is an open access article distributed under the Creative Commons Attribution License, which permits unrestricted use, distribution, and reproduction in any medium, provided the original work is properly cited.

Objectives. We have developed a pulsed xenon ultraviolet light-based real-time air disinfection system with rapid and effective disinfection by using high-intensity pulse germicidal UV. Disinfection of the ambulance's environment is critical in the prevention of infectious cross contamination. Methods. In this study, a pulsed xenon ultraviolet light-based air disinfection system was established for real-time air disinfection in ambulances. In this system, a pulsed xenon ultraviolet (PX-UV) was used to generate broad-spectrum $(200-320 \mathrm{~nm})$, high-intensity ultraviolet light to deactivate and kill bacteria and viruses. The results showed that the use of PX-UV could be effective in reducing E. coli, Staphylococcus albus, and environmental pathogens level in ambulances ( $\geq 90 \%$ reduction in 30 mins). Results. This device was relatively simple and easy to use and does not leave chemical residues or risk exposing patients and workers to toxic chemicals. Conclusions. This appears to be a practical alternative technology to achieve automated air disinfection in ambulances.

\section{Introduction}

Hundreds of millions of patients around the world are affected by health care-associated infections (HCAI) each year, and despite the presence of many disinfection methods, microbial contamination remains a significant health concern throughout the world $[1,2]$. The ambulance is one of the most common and important types of medical transport in the hospital emergency system. It is responsible for transferring individuals that are severely injured or ill. Because of the special construction and the narrow space inside, ambulances are frequently contaminated with pathogenic microorganisms shed by patients during prehospital transport, which would be transferred to subsequent patients and emergency medical service workers. Previous studies have demonstrated that ambulances operating in the emergency medical services (EMS) system may have a significant degree of MRSA contamination $[3,4]$. These results demonstrated that ambulances represent an important reservoir for infectious microorganisms during an infectious disease pandemic, when large numbers of highly contagious patients would be transported. Disinfection of the ambulance's environment is critical in the prevention of infectious cross contamination. Chemicals such as chlorine dioxide and hydrogen peroxide disinfectant have traditionally been used for ambulance disinfection after used by infectious patients. However, manual chemical disinfection is tedious, time- 
consuming, and hazardous to the workers and the environment. Several studies have shown that persistent contamination is commonly found in patient compartment even after cleaning $[5,6]$. During an infectious disease pandemic, a large number of highly contagious patients need to be transported and it requires ambulances return to service as soon as possible. In that case, separate routine cleaning is not sufficient to eliminate these pathogens. To control the cross infection in ambulances, good disinfection routines based on cleaning and disinfection of ambulances contaminated with highly contagious microorganisms are obligatory requirements.

Ultraviolet (UV) irradiation has been proposed as a terminal disinfection method in a variety of applications. The UV radiation covers the wavelength range from 100 to 380 nanometers. At certain wavelengths, the mechanism of killing of microorganisms by UV is primarily due to the breakage of the molecular bonds in DNA and RNA through absorption of photons resulting in formation of pyrimidine dimers from thymine and cytosine [7]. Specifically, previous studies discovered that UV radiation emitted at 254 nanometer $(\mathrm{nm})$ was the most effective $[8,9]$. Most UV room disinfection devices use mercury gas bulbs as a light source which has a characteristic wavelength of $254 \mathrm{~nm}$ [10]. The ultraviolet radiation emitted by low-pressure mercury bulbs is delivered in a continuous stream that gradually accumulates to lethal doses depending on the duration of exposure and distance from the primary field of radiation [11]. Pulsed xenon ultraviolet (PX-UV) is an attractive alternative to traditional UV methods offering high-intensity pulse germicidal UV. It is emitted in short, high-intensity pulses, possibly requiring a shorter duration of exposure to achieve lethal doses. PX-UV light may have greater efficacy than other forms of UV, such as mercury UV, because of the broad spectrum and a greater intensity [11]. Haddad et al. have shown that the use of PX-UV as a supplementing standard cleaning procedure helped reduce bacterial contamination levels [12]. Jinadatha et al. have shown that the use of PX-UV was more effective than standard manual room terminal cleaning in reducing levels of known pathogens [13-15]. To the best of our knowledge, a PV-UV-based disinfection device for real-time air disinfection in ambulances has not been previously reported.

The purpose of the current study was to validate a pulsed xenon ultraviolet disinfection device for real-time air disinfection in ambulances and to assess whether this device was effective in terms of reducing environmental pathogens contamination in ambulances.

\section{Experimental Section}

2.1. Device Setup. The configuration of the real-time air disinfection device is shown in Figure 1. The unit is an enclosed air disinfection device incorporated into an ambulance fixture, where a pulsed xenon UV lamp is used as the light source, which can emit a broad spectrum of $200 \mathrm{~nm}-320 \mathrm{~nm}$. The lamp was powered by a pulsed power source. The PX-UV system produces a pulsed flash at a frequency of $30 \mathrm{~Hz}$ with an approximate output of $270 \mathrm{~J}$ per pulse and a duration of less than $360 \mathrm{~ms}$. The pulsed xenon

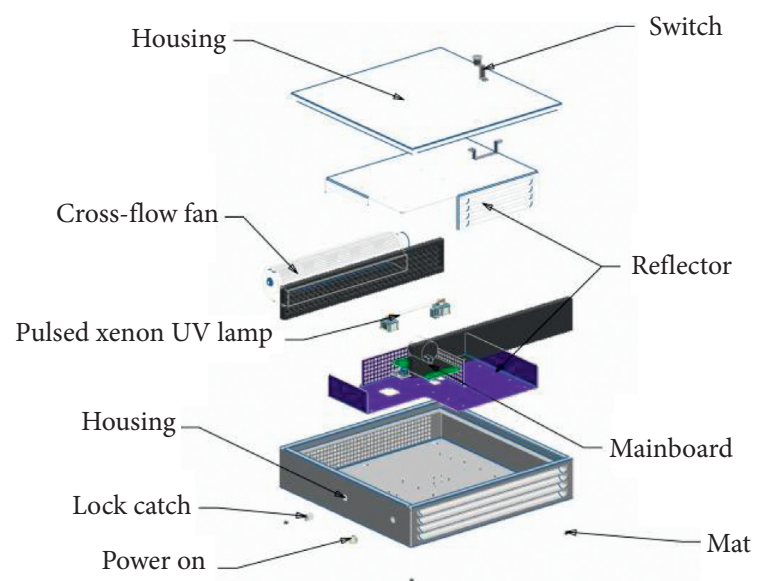

Figure 1: Experimental configuration of the pulsed xenon ultraviolet disinfection device (the size of the device is $505 \times 500 \times 120 \mathrm{~mm})$.

UV lamp was placed in the center of a reflective, aluminumcovered chamber to continuously purify the air. The air flows through the processing chamber with an internal cross-flow fan with a flow rate of $5.4 \mathrm{~m}^{3} / \mathrm{min}$. In this case, the cross-flow fan has two functions: (1) driving the air into the device and (2) cooling the pulsed xenon UV lamp. The reflectivity of the aluminum is proposed to enhance the light reflection efficiency and increase the time that the pulsed light is in contact with the air, thereby improving the germicidal activity of the apparatus. The air outlet was made in the form of shutters to block UV radiation.

\subsection{Preparation of Bacterial Suspension. E. coli (ATCC 8099)} and Staphylococcus albus (ATCC 8799) were used as the model bacteria to evaluate the sterilization effect. E. coli (ATCC 8099) and Staphylococcus albus (ATCC 8799) were obtained from Beijing Beina Chuanglian Biotechnology Institute and grown in the nutrient broth and nutrient agar at $36^{\circ} \mathrm{C} \pm 1{ }^{\circ} \mathrm{C}$ for 24 hours, followed by centrifugation at $3,300 \times \mathrm{g}$ for $30 \mathrm{~min}$. The bacteria were resuspended in $0.1 \mathrm{M}$ phosphate buffer. A turbidimeter was used to prepare a bacterial suspension with a concentration of $1.5 \times 10^{8} \mathrm{CFU} /$ $\mathrm{mL}$ to $3.0 \times 10^{8} \mathrm{CFU} / \mathrm{mL}$. The prepared bacterial suspension will be ready for use.

2.3. Bacterial Suspension. The bacterial suspension was diluted with PBS buffer solution (the concentration of $E$. coli and Staphylococcus suspension was $1.20 \times 10^{6} \mathrm{CFU} / \mathrm{mL}$ and $1.40 \times 10^{6} \mathrm{CFU} / \mathrm{mL}$, respectively). The diluted bacterial suspension was loaded in an aerosol generator (atomization effect $>90 \%$, particle size $<5 \mu \mathrm{m}$ ). This quasiexperimental study was conducted in two biosafety cabinets. The microbial aerosol generator was placed in biosafety cabinets (NUAIRE NU 437 600S). Air spray was carried out under the following conditions: the room temperature is $20^{\circ} \mathrm{C}$ to $25^{\circ} \mathrm{C}$, and the relative humidity is $50 \%$ to $70 \%$. The spraying time was $5 \mathrm{~min}$ and stationary for $1 \mathrm{~min}$. The airborne bacterial populations were sampled by impaction directly onto nutrient agar plates, using a Merck MAS-100 air 
TABle 1: Effectiveness of the real-time air disinfection device against $E$. coli in the air.

\begin{tabular}{lccccccc}
\hline Time $(\mathrm{min})$ & No. & $V_{0}\left(\mathrm{Cfu} / \mathrm{m}^{3}\right)$ & $V_{t}\left(\mathrm{Cfu} / \mathrm{m}^{3}\right)$ & $N_{t}(\%)$ & $V_{o}^{\prime}\left(\mathrm{Cfu} / \mathrm{m}^{3}\right)$ & $V_{t}^{\prime}\left(\mathrm{Cfu} / \mathrm{m}^{3}\right)$ & $K_{t}(\%)$ \\
\hline \multirow{3}{*}{30} & 1 & $2.70 \times 10^{5}$ & $1.76 \times 10^{5}$ & 34.81 & $2.64 \times 10^{5}$ & 0 & 100 \\
& 2 & $2.54 \times 10^{5}$ & $1.66 \times 10^{5}$ & 34.65 & $2.40 \times 10^{5}$ & 0 & 100 \\
& 3 & $2.10 \times 10^{5}$ & $1.40 \times 10^{5}$ & 33.33 & $2.10 \times 10^{4}$ & 0 & 100 \\
\hline
\end{tabular}

$N_{t}$ : the natural extinction rate of bacteria in the air; $V_{0}$ and $V_{t}$ : the amount of bacteria in the air at different times before and during the experiment was conducted; $V_{o}^{\prime}$ and $V_{t}^{\prime}$ : the amount of bacteria in the air at different times before and during the disinfection process of the experimental group; $K_{t}$ : the disinfection rate of bacteria in air.

TABle 2: Effectiveness of the real-time air disinfection device against Staphylococcus albus in the air.

\begin{tabular}{lccccccc}
\hline Time $(\mathrm{min})$ & No. & $V_{0}\left(\mathrm{Cfu} / \mathrm{m}^{3}\right)$ & $V_{t}\left(\mathrm{Cfu} / \mathrm{m}^{3}\right)$ & $N_{t}(\%)$ & $V_{o}^{\prime}\left(\mathrm{Cfu} / \mathrm{m}^{3}\right)$ & $V_{t}^{\prime}\left(\mathrm{Cfu} / \mathrm{m}^{3}\right)$ & $K_{t}(\%)$ \\
\hline \multirow{3}{*}{30} & 1 & $2.64 \times 10^{5}$ & $1.76 \times 10^{5}$ & 33.33 & $2.64 \times 10^{5}$ & 160 \\
& 2 & $2.44 \times 10^{5}$ & $1.51 \times 10^{5}$ & 38.11 & $2.52 \times 10^{5}$ & 150 & 99.91 \\
& 3 & $2.31 \times 10^{5}$ & $1.40 \times 10^{5}$ & 39.39 & $2.40 \times 10^{5}$ & 130 \\
\hline
\end{tabular}

$N_{t}$ : the natural extinction rate of bacteria in the air; $V_{0}$ and $V_{t}$ : the amount of bacteria in the air at different times before and during the experiment was conducted; $V_{o}^{\prime}$ and $V_{t}^{\prime}$ : the amount of bacteria in the air at different times before and during the disinfection process of the experimental group; $K_{t}$ : the disinfection rate of bacteria in air.

sampler. This was followed by the use of the PX-UV system, for 30-minute exposure. Replace the agar plate in the sampler and take the second sampling after 30 minutes. A control experiment was conducted as described above but without having been exposed to the PX-UV system. All plates were incubated at $36^{\circ} \mathrm{C} \pm 1^{\circ} \mathrm{C}$ for $24 \mathrm{~h}$.

$$
\begin{aligned}
& N_{t}=\frac{V_{0}-V_{t}}{V_{0}} \times 100 \%, \\
& K_{t}=\frac{V_{0}^{\prime}\left(1-N_{t}\right)-V_{t}^{\prime}}{V_{0}^{\prime}\left(1-N_{t}\right)} \times 100 \%,
\end{aligned}
$$

where $N_{t}$ is the natural extinction rate of bacteria in the air, $V_{0}$ and $V_{t}$ are the amount of bacteria in the air at different times before and during the experiment was conducted, $V_{0}^{\prime}$ and $V_{t}^{\prime}$ are the amount of bacteria in the air at different times before and during the disinfection process of the experimental group, and $K_{t}$ is the disinfection rate of bacteria in air.

2.4. Field Air Disinfection Test. To test the ability of the PXUV system to disinfect pathogens in ambulances, we choose the ambulances that just returned to the hospital for their reasoned propensity to yield a large spectrum of bacteria. According to the ambulance instruction manual, the volume of the ambulance therapeutic cabin is approximately $10 \mathrm{~m}^{3}$. Before starting the disinfection device, a Merck MAS-100 air sampler was used to influence $1 \mathrm{~L}$ air onto blood agar plates before and after the pulsed xenon ultraviolet (PX-UV) disinfection for 60 minutes. All the plates incubated at $36^{\circ} \mathrm{C} \pm 1^{\circ} \mathrm{C}$ for $24 \mathrm{~h}$. All bacteria and fungi colony forming units were counted, and the airborne bacterial count and killing rate were calculated:

$$
\text { Killing rate }(\%)=\frac{\text { Bacterial count before disinfection }- \text { bacterial count after disinfection }}{\text { Bacterial count before disinfection }} \text {. }
$$

\section{Result and Discussion}

In this study, we used E. coli and Staphylococcus albus as models to test the disinfection effect of PX-UV. Tables 1 and 2 show the E. coli and Staphylococcus albus concentration levels before and after the PX-UV treatment, respectively. It can be seen that the 30-min PX-UV treatment reduces the $E$. coli concentration which is lower than the detection level, while the PX-UV treatment results in 99.91\% Staphylococcus albus disinfection. UV can kill bacteria, viruses, fungi, and spores, but different types of microorganisms have different sensitivity to UV, Gram-negative bacteria are the most sensitive, followed by Staphylococcus [16]. The available reason for this case is that $E$. coli is more sensitive to UV light than Staphylococcus albus. Therefore, it is seen that PX-UV treatment for more than 30 mins has an apparent effect in reducing the bacteria concentration levels to a value compatible with the guidelines.

The disinfection efficiency of the real-time PX-UV disinfection device was evaluated by measuring the bioaerosol levels of natural bacteria before and after disinfection. The experimental results found that the average disinfection rate of natural bacterial aerosols was found to be more than $90 \%$ after 60 mins of disinfection, which was lower than that of the laboratory simulation test (see Table 3). Because of the harsh living conditions in the natural environment, the survival ability of the living microorganisms and the ability to resist external interference are stronger than those used in the 
TABLE 3: Disinfection efficiency of the real-time PX-UV for natural bacteria in ambulances.

\begin{tabular}{lcccc}
\hline Time (min) & No. & $\begin{array}{c}\text { Before } \\
\left(\mathrm{Cfu} / \mathrm{m}^{3}\right)\end{array}$ & After $\left(\mathrm{Cfu} / \mathrm{m}^{3}\right)$ & Killing rate (\%) \\
\hline \multirow{3}{*}{60} & 1 & 480 & 30 & 93.75 \\
& 2 & 490 & 40 & 91.84 \\
& 3 & 400 & 40 & 90.00 \\
\hline
\end{tabular}

laboratory. Thus, using a real-time PX-UV disinfectant to maintain the air quality is of great importance to reduce cross infection in ambulances.

\section{Conclusions}

In conclusion, we have developed a pulsed xenon ultraviolet light-based real-time air disinfection system with rapid and effective disinfection by using high-intensity pulse germicidal UV. Our design is an enclosed air disinfection device, which can be operated in the presence of people. The device is powered by an ambulance and can be operated automatically as the ambulance starts.

In our study, we found that the real-time air disinfection device reduced the number of E. coli and Staphylococcus albus on the biological safety cabinet with a 30-minute exposed time and foresaw a positive effect. Similarly, because of the complex environment of the actual site, only $90 \%$ of the bactericidal results have been achieved. Although the disinfection effect has not reached more than $99 \%$, the efficacy of the real-time air disinfection device could get the desired results in real-world settings. The results of this study suggest that the home-made PX-UV disinfection device can provide real-time and effective disinfection for ambulance application.

In actual use, some problems with the real-time air disinfection device have been discovered. The first is the ventilation problem. The space for an ambulance is approximately $10 \mathrm{~m}^{3}$. Does the air in the ten cubic meters of space is completely sterilized by the device instead of being sterilized clean air all the time? Secondly, the contact surface of the equipment considering the disinfection air needs to be large enough and the shape of the designed instrument needs further improvement. The space in the cabin is limited, with excellent disinfection effects while saving space as much as possible, so that the medical staff can have enough space to treat patients. For these problems, we also need to further design and improve the instrument to produce a better device to achieve higher and more effective disinfection.

\section{Data Availability}

No data were used to support this study.

\section{Disclosure}

Li Song and Wei Li are the co-first authors.

\section{Conflicts of Interest}

The authors declare that they have no conflicts of interest.

\section{Acknowledgments}

This work was supported by the National Key Research and Development Program of China (nos. 2018YFC0809200 and 2016YFF0203203), National Natural Science Foundation of China (no. 81703271), Guangdong Science and Technology Foundation (no. 2016A020219005), Shenzhen Science and Technology Foundation (nos. SGLH20180625171602058, CKCY20170720100145297, JCYJ20170307104024209, and JCYJ20160427151920801), and Open project of Key Laboratory of Tropical Disease Control of Ministry of Education (Sun Yatsen University) (no. 2019kfkt06).

\section{References}

[1] M. Galtelli, C. Deschamp, and J. Rogers, "An assessment of the prevalence of pathogenic microorganisms in the rotor wing air ambulance: one program's findings," Air Medical Journal, vol. 25, no. 2, pp. 81-84, 2006.

[2] M. E. A. de Kraker, P. G. Davey, H. Grundmann, and On behalf of the BURDEN study group, "Mortality and hospital stay associated with resistant Staphylococcus aureus and Escherichia coli bacteremia: estimating the burden of antibiotic resistance in Europe," PLoS Medicine, vol. 8, no. 10, Article ID e1001104, 2011.

[3] C. E. Roline, C. Crumpecker, and T. M. Dunn, "Can methicillin-resistant Staphylococcus aureus be found in an ambulance fleet?," Prehospital Emergency Care, vol. 11, no. 2, pp. 241-244, 2007.

[4] R. Brown, J. Minnon, S. Schneider, and J. Vaughn, "Prevalence of methicillin-resistant Staphylococcus aureus in ambulances in southern Maine," Prehospital Emergency Care, vol. 14, no. 2, pp. 176-181, 2010.

[5] B. D. Tanner, "Reduction in infection risk through treatment of microbially contaminated surfaces with a novel, portable, saturated steam vapor disinfection system," American Journal of Infection Control, vol. 37, no. 1, pp. 20-27, 2009.

[6] M. Stibich, J. Stachowiak, B. Tanner et al., "Evaluation of a pulsed-xenon ultraviolet room disinfection device for impact on hospital operations and microbial reduction," Infection Control \& Hospital Epidemiology, vol. 32, no. 3, pp. 286-288, 2011.

[7] M. U. Owens, D. R. Deal, M. O. Shoemaker, G. B. Knudson, J. E. Meszaros, and J. L. Deal, "High-dose ultraviolet C light inactivates spores of Bacillus atrophaeus and Bacillus anthracis sterne on nonreflective surfaces," Applied Biosafety, vol. 10, no. 4, pp. 240-247, 2005.

[8] W. W. Stead, "Clearing the air: the theory and application of ultraviolet air disinfection," American Review of Respiratory Disease, vol. 140, no. 6, p. 1832, 1989.

[9] J. J. Mcdevitt, S. N. Rudnick, and L. J. Radonovich, “Aerosol susceptibility of influenza virus to UV-C light," Applied and Environmental Microbiology, vol. 78, no. 6, pp. 1666-1669, 2012.

[10] W. J. Kowalski, W. P. Bahnfleth, D. L. Witham, B. F. Severin, and T. S. Whittam, "Mathematical modeling of ultraviolet germicidal irradiation for air disinfection," Quantitative Microbiology, vol. 2, no. 3, pp. 249-270, 2000.

[11] J. Levin, L. S. Riley, C. Parrish, D. English, and S. Ahn, "The effect of portable pulsed xenon ultraviolet light after terminal cleaning on hospital-associated Clostridium difficile infection in a community hospital," American Journal of Infection Control, vol. 41, no. 8, pp. 746-748, 2013. 
[12] L. E. Haddad, S. S. Ghantoji, M. Stibich et al., "Evaluation of a pulsed xenon ultraviolet disinfection system to decrease bacterial contamination in operating rooms," BMC Infectious Diseases, vol. 17, no. 1, p. 672, 2017.

[13] C. Jinadatha, R. Quezada, T. W. Huber, J. B. Williams, J. E. Zeber, and L. A. Copeland, "Evaluation of a pulsed-xenon ultraviolet room disinfection device for impact on contamination levels of methicillin-resistant Staphylococcus aureus," BMC Infectious Diseases, vol. 14, no. 1, pp. 1-7, 2014.

[14] C. Jinadatha, F. C. Villamaria, M. I. Restrepo et al., "Is the pulsed xenon ultraviolet light no-touch disinfection system effective on methicillin-resistant Staphylococcus aureus in the absence of manual cleaning?," American Journal of Infection Control, vol. 43, no. 8, pp. 878-881, 2015.

[15] C. Jinadatha, F. C. Villamaria, N. Ganachari-Mallappa et al., "Can pulsed xenon ultraviolet light systems disinfect aerobic bacteria in the absence of manual disinfection?," American Journal of Infection Control, vol. 43, no. 4, pp. 415-417, 2015.

[16] C. W. Mckinney and A. Pruden, "Ultraviolet disinfection of antibiotic resistant bacteria and their antibiotic resistance genes in water and wastewater," Environmental Science \& Technology, vol. 46, no. 24, pp. 13393-13400, 2012. 